\title{
13. The View from 'Home'- Transnational Movements from Three Tongan Villages
}

\section{Steve Tupai Francis}

In this paper, my goal is to explore the dichotomy of 'home' and 'host' posited in studies of transnationalism. I intend to do this by examining the very different forms of migration I found in conducting fieldwork in three Tongan villages. I argue that the view from 'home' is often a missing aspect in explorations of transnationalism. This is not particularly surprising given the focus in these studies on the networked connections of diasporic peoples and communities. As is documented in this collection, Pacific Islanders have travelled far from Oceania to reside in Australia, New Zealand, the United States and other countries; they strongly identify themselves with their 'home' places; and they continue to interact socially, culturally, financially and politically with these places of origin.

There are two elements of transnationalism that are pertinent in the context of this discussion: the processes (cultural, social, economic, political) of exchange that occur between those living in the homeland and those in the place of migration; and the new forms of cultural, social and economic interaction that are created as a result of the interplay of these exchanges (Hannerz 1992).

The strength of these connections is such that migrants living in diasporic communities need never return to their homeland in order to legitimately participate in these cross-border exchanges. In fact, transnational actors do not need to have been born in the 'homeland' to identify strongly with the country of origin of their parents or grandparents, and to participate in diasporic transactions. Similarly many of those who remain at 'home' and who participate in these transnational processes, may never have travelled overseas themselves. This is the true power and agency of the transnational connections represented by family networks (Basch et al. 1994; Ong 1999).

While much work has focused on the lives of migrants and the impact of their diasporic movements and the nature of their connections to homeland, little research has focused on the transnational behaviours, movements, actions and perspectives of those remaining at 'home'.

Additionally, although transnationalism and the examination of the connections between 'home' and the places to which people move is purely the study of movement itself, theorists can be guilty of fixing people and place in time and 
space. For example, the focus on Tongan migration or Samoan transnational practices, in a way, does not allow for difference within and between island cultures, or between islands and villages for that matter. The reality, as always, is more interesting and complex. The ways, means and reasons for movement are not so easily fixed.

As pointed out by Nakhid (this volume), reciprocity is central to transnationalism. My concern in this paper is therefore to analyse and explain the factors that enable people to become transnational in the first place. Factors such as opportunity and quality of connections to other places are core elements in this discussion.

\section{Three Villages in Tonga}

My research in Tonga demonstrated that transnational practices can differ markedly among island nations and that patterns of movement into and out of villages can be identified. Variables such as history, origin and socio-economic context greatly affect how transnational movements are enacted and transacted. In researching transnational practices in the Pacific islands, fieldwork was undertaken in three Tongan villages: Lotofoa in the outer islands; Hofoa, which is close to the capital city of Nuku'alofa and 'Isileli, a newly created village of outer island migrants close to Nuku'alofa. A brief description of each village follows.

Located on the island of Foa in the outer Ha'apai island group, Lotofoa is characterised by other Tongans as 'traditional', a nomenclature often bestowed on all the peoples of Ha'apai. This distinction is both respectful, with an implication that the people of Ha'apai remember the old ways and keep to the old traditions unlike those who grew up on Tongatapu, and derogatory, with an implication of backwardness. According to one villager, Lotofoa was once the capital of Ha'apai and its wharf was the centre of trade and commerce in the cluster. Sailing boats called vakalā were used to ply the waters between Ha'apai and Tongatapu, taking produce and livestock to Tongatapu for sale. Another local indicated that trips to New Zealand were also undertaken.

The population relies primarily on subsistence cropping and harvesting of sea resources for their daily needs. Most families are able to use plantation land for subsistence purposes while a small number of farmers generate larger incomes through cash-cropping. Wage employment is a viable option for very few residents of the village due to the small-scale infrastructure of the Ha' apai cluster. While there are a number of government departments, some retail and tourism businesses, and a hospital all located in the capital Pangai, competition for the limited jobs available is intense.

Cash in the village is acquired primarily through the remittances of family living in other parts of Tonga or overseas, the sale of produce or sea harvest in Pangai 
or in the capital Nuku'alofa, or through profits made by small businesses such as the falekoloa (food/goods stores) that line the main roads of all Tongan villages. The relatively lower per capita income generated in Lotofoa is reflected in the higher proportion of traditional dwellings such as the faleTonga (thatched hut) in comparison to European-style housing. There is a group of entrepreneurs in the village however, who are able to generate cash surpluses through cropping and other business interests. Their success derives primarily from the ability to combine an understanding of basic business principles and cash generation with access to farming equipment such as tractors and ploughs. ${ }^{1}$ Much of this equipment was purchased through savings acquired during work in overseas factories or through remittances from Tongan relatives living in Pacific Rim countries. These capital purchases have enabled these farmers to cultivate larger tracts of agricultural land and sell the resulting agricultural produce in the markets of Nuku'alofa (as distinct from the local markets of Ha'apai) where higher returns may be obtained. Finally, the population of Lotofoa has been decreasing for the past 100 years. This general observation masks the more complex movement flows that are taking place in the village.

Situated on the central northern coast of the main island of Tonga, Tongatapu, Hofoa is a medium-sized long-established Tongan village. Encompassing an area of approximately one square kilometre, the population live on 'api kolo 'town allotments' clustered along the central road leading through the village. From informant accounts, it appears that Hofoa was not originally established as a fort in the manner of other villages; rather, the area was plantation land later claimed by the royal family and transferred to the government.

The proximity of Hofoa to the capital allows young people of the village easy access to the superior secondary school system of Tongatapu. ${ }^{2}$ As a result, Hofoa has a relatively highly educated population and consequently, many are employed in the government bureaucracy and the service sector, as well as operating small businesses or participating in the trades. Located in an arc surrounding the village, most families in Hofoa have access to or own an 'api uta/tukuhau (bush/plantation allotment). Cash-cropping is relatively rare, with most households growing small amounts of subsistence and ceremonial foods to supplement other subsistence and income-earning activities. There are some small-scale practices that earn cash to supplement wages, including the selling of surplus produce from gardens or fish caught on the nearby reef locally, through word of mouth or in a roadside falekoloa or in the markets of Nuku'alofa.

The people of Hofoa could be characterised as prosperous in comparison with other villagers of Tongatapu and certainly when compared to those in the outer islands. There are many indicators of this status in the village, including the high proportion of per capita car, truck and boat ownership as well as a predominance of well maintained, European-style housing. Five village churches 
(of various Christian denominations), four fale koloa and four church halls, which also become kava clubs several nights a week, serve as the primary sites of village social interaction and activity. The fono (village meetings) and social/life-stage events that take place at these venues continue to be announced to the community in the traditional way as the 'ofisi kolo (town officer) strides up and down the main street heralding the events in a loud voice.

Many villagers have travelled and lived in Pacific Rim countries and many households receive remittances from kin living overseas. Hofoa is also subject to a constant flow of population into and out of the village, as kin living in other parts of Tonga and overseas visit their relatives and friends in the village.

The densely populated, recently established community of 'Isileli on Tongatapu is situated on land reclaimed from the swamp to the north-east of Hofoa, approximately 2.5 kilometres from Nuku'alofa. The area was designated as a resettlement zone by the Tongan government in 1983 for people whose houses and villages were destroyed by Hurricane Isaac. Bounded in the west by the road leading to Hofoa from the ocean and southern fringe of 'api uta owned by the people of Kolomotu'a, the area in which 'Isileli is situated has never previously been used for human habitation. ${ }^{3}$ Constantly flooded after heavy rain and suffering poor drainage, the village population has steadily increased following the original emergency settlement. Subsequently, migrants from all island clusters of Tonga targeted 'Isileli and the nearby village of Sopu as a point of settlement. The proximity of these villages to Nuku'alofa offers residents easy access to the education, employment, family and lifestyle opportunities offered by the capital.

The area is designated as tofi'a puleanga (government estate). As a result, 'api kolo (town allotments) are allocated and distributed by the Department of Lands. The land on which 'Isileli is situated was stabilised by rock quarried from coral deposits in the south of Tongatapu and transferred to the land allotments purchased from the government. These blocks tend to be much smaller than the average 'api kolo found in older Tongan villages. Large, empty sections of low-lying land on the outskirts of the village await the arrival of new settlers. This leads to the somewhat incongruous sight of small houses rising out of the swamp like islands surrounded by as yet unclaimed 'api kolo.

The government considers neither Sopu nor 'Isileli as a village in its own right. Incorporated within the larger and older district of Kolomotu'a, is home to most of the Kingdom's nobles, these communities do not have their own town officer. Despite the fact that both villages have developed identities separate from Kolomotu'a, administrative and governmental structures have not kept pace with these developments.

Unlike Hofoa however, there are no plantation lands accessible to the population as all available arable land has been under cultivation by the people of Hofoa 
and Kolomotu'a for a number of generations. This has limited the ability of 'Isileli residents to grow subsistence crops. Some householders in 'Isileli from other parts of Tongatapu are able to use the land of friends or family in the area. There are also some toutu'u (collective garden) groups in the village, although that land is situated in another area of the island. For most people however, food is purchased from the market in Nuku'alofa.

As a village of migrants, there are few kinship connections between the residents of 'Isileli. Intravillage ties tend to be established through religious affiliation or via village or island-of-origin links rather than through kinship or marriage. As a result, the village has a very different 'feel' from others in Tonga. Important factors contributing to this difference include the combination of tenuous cross-cutting kinship ties and the constant arrival of new residents.

The people of 'Isileli are also more reliant on the modern monetary economy of Tonga than the populations of other Tongan villages. Lacking plantation land for the production of subsistence or cash crops, families must rely on the accumulation of capital through unskilled wage labour, small business, the bureaucracy, trades or professions. As a result, there is an uneven distribution of wealth within the village, with some very poor families (often with low levels of education, poor health and poor living conditions) and some very well-off families (usually business people, entrepreneurs and professionals). Housing is the marker of this disparity: small shanty-like dwellings constructed from drift wood and 'found' materials sot next to large multistorey American kit homes. Also reflecting the mobility of those living in the village, a large number of villagers have travelled extensively within Tonga and throughout Pacific Rim countries. Consequently, a high level of remittance is also apparent.

'Isileli is a place of dualisms, of 'haves' and 'have nots', of those who have travelled extensively and those who have not, those who receive regular remittance income from overseas relatives and those who do not, those who access wealth and those who do not.

\section{Travel and Distance: Comparing Three Tongan Villages}

In order to draw out the variations and differences in transnational connections and movements that can occur even within ostensibly 'culturally bounded' island societies, this section compares the different ways and means by which Tongans move through time and space.

The journeys undertaken by people from Lotofoa primarily involve movements between the Ha'apai and Tongatapu clusters. For example, in one year I found that 96 per cent of those departing the village for a location in the Kingdom of Tonga travelled to Tongatapu; 23 per cent of the total village population made a total of 180 journeys to Tongatapu; in approximately 76 per cent of households, at least one member made a journey to another island cluster of Tonga. 
A distinctive feature of movement in Lotofoa is the frequency of short-term movement. A comparison of the data reveals that the people of Lotofoa $(n=187)$ made more than three times the number of journeys within Tonga in comparison to those in Hofoa and 'Isileli. For the people of Lotofoa, travel is an essential requirement for completing certain tasks, journeys that are unnecessary for those living on Tongatapu. These journeys are most often short to medium term, and primarily focused on Tongatapu.

Religion has played a key role in facilitating journeys made by the people of Lotofoa. Religious affiliation has enabled exchange visits between church groups in Tonga and overseas, travel by church choirs to and from Lotofoa to other sites, and journeys made to attend meetings of church organisations such as the kau akonaki, the women's assembly of the Free Wesleyan Church of Tonga, the Monarch's church. For the people of Lotofoa, religion was the primary reason for departure from the village for 33 per cent of those not present at the time of the second census in this village, one year after the first census. Most of these absentees were attending the Konifelenisi (religious conference) celebrations of their churches in Nuku'alofa on Tongatapu. Other villagers from Lotofoa were also overseas, in New Zealand, as part of an evangelio (evangelist) contingent of young people spreading the Christian gospel.

The importance of education in fostering movement is evident to anyone present in Lotofoa during school holidays or the Christmas period. The population doubles in size as school-age children and their parents or other guardians return from Tongatapu following the conclusion of the school term or year. Over 10 per cent of those departing the village left for education purposes, and correspondingly, 11 per cent of those returning to the village cited home after education as the reason for their return.

Selling produce was also a key factor for those departing (7 per cent) and returning (6 per cent). While there is a small market in the Ha'apai capital of Pangai, the produce market in Nuku'alofa (Tongatapu) is the primary site for selling cash crops because of the superior prices paid to growers. A number of farmers and their families transported their crops on the weekly inter-island ferry and sold them in Tongatapu. Most stayed with family while in Tongatapu, undertaking other activities while there. These included processing visas for overseas stays, purchasing goods unavailable in the outer islands as well as 'alu 'eva pe (going for a visit).

The following case study is a useful example of these forms of movement out of and in to Lotofoa. In one Lotofoa family of two parents and six children, the male head, Semisi, was frequently absent. A minister in one of the poorer village churches, he travelled to New Zealand at the time I conducted a household survey. He was working and visiting his brother for three months to try to 
improve the family's finances. He also attended the Konifelenisi of his church earlier in the year.

During the month of the survey, with the head of the household in New Zealand, the family faced a daily struggle to address basic subsistence needs. These were eventually met through the sale and exchange of lalanga (woven mats) made by the female head and sold in the village, access to subsistence produce (basic root vegetables) grown in a church toutu'u as the family did not have a plot of their own, and the generosity of family, neighbours and parishioners in the village who donated food and produce to the family. While Semisi's sojourn overseas did result in his returning to the village with a small amount of cash savings, the impact of the overseas movement on the family was quite negative in the short term.

In comparison with Lotofoa, the movement of people from the village of Hofoa has much more of an 'international' focus. For example: 51 per cent of people departing the village travelled to an international location; in 40 per cent of households, at least one member made a journey overseas; 10 per cent of the village population made a total of 109 journeys to international locations; New Zealand was the country of destination for 61 per cent of those making international journeys. The range of international sites available to people from Hofoa are significantly greater than for those living in Lotofoa or 'Isileli. Residents of Hofoa had a greater proportion of parents, siblings and children, in particular, residing overseas. These close ties mean that activating connections is easy.

Hofoa is a conduit for international movement in that population flow involves inward moves to Hofoa from the outer islands, return movements from overseas and external moves from Hofoa to international destinations. A key factor is the number of family members from Hofoa established in international sites, who provide a larger range of available close kin ties (i.e., parental, sibling, children) of which these villagers can take advantage.

Socio-cultural factors are the most important motivators in encouraging movement among villagers from Hofoa. Visiting family or attending life-stage events such as weddings and funerals are key motivators for movement out of this village. This is also underscored by the primacy of these factors in the movement of villagers from Hofoa to other parts of Tonga. A useful example of this type of movement is demonstrated in the following case study. One household visited frequently in Hofoa comprised a woman and her four children, her friend and her friend's child. Living in a two-room shack on the 'api kolo of her father, Mele, the female head of this household, was the only adult member of her immediate family who continued to reside in Tonga. All of her close kin lived in New Zealand, including her partner, her eight siblings, parents and their siblings. Only one year later, Mele and all her children had moved to New Zealand, leaving the 'api kolo to her friend. 
During this time, two of Mele's children moved to live in New Zealand with their grandparents. Meanwhile, her mother also returned to Tonga for two months when Mele fell ill. Mele's father also returned for two weeks to attend a particularly important putu (funeral) upon the death of his fa'e tangāta (mother's brother).

The story of this household is dominated by the impact of movement in the context of maintaining the social, cultural, and ritual responsibilities associated with being Tongan. With all her family living in New Zealand, Mele was obliged to facilitate, organise, participate in and contribute to all life-stage events and other cultural obligations on behalf of her family. In other words, in the context of mass out-movement, she assumed the burden of kavenga (ritual obligation) on behalf of her entire family. In one 30-day period, I recorded the following activities:

Mele attended and contributed to six putu including a week in 'Eua and extended participation in a funeral that required a week living in the household of the deceased.

In a car paid for by family in New Zealand, she daily transported kin and neighbours to town, to the market and to the tahi (ocean) to fish and do the shopping, and pick up packages at the wharf or post office.

Mele continuously ran errands and tasks during the extended chronic illness of a close extended-family member. She was involved in purchasing groceries, cooking food, transporting kin of the relative to hospital to have a baby, and ferrying other family members to and from the airport, a two-hour round trip.

She frequently organised, through international phone calls to her parents in New Zealand, for money to be sent to purchase the requisite koloa (traditional valued goods) for the funerals attended. Money was continually funnelled into the household from New Zealand to pay for these gifts and other expenses associated with the funerals she attended.

When I commented that she was very busy, Mele stated that she was having to deal with fua kavenga, meaning 'a lot' of kavenga, a 'heavy' kavenga burden. She was not bemoaning the fact that she had to fulfil these responsibilities; that is simply a given in Tongan society. Rather, she was commenting on the fact that the movement of her family overseas had greatly increased the movements she had to undertake within Tonga in order to sustain relationships on behalf of the family.

The characteristics of movement associated with the village of 'Isileli was very different to that of Lotofoa and Hofoa. Over a one-year period: 75 per cent of those leaving the village travelled to a location within Tonga; in 35 per cent of households, at least one member made a journey to other island clusters of Tonga; 
15 per cent of the village population made a total of 109 journeys to locations within Tonga; Ha'apai was the destination for 61 per cent of these people.

One of the factors in this movement was the relatively recent arrival of most people living in the village. A distinctive feature of households in this village is the way in which many of the 'api's (houses) in the village were used by groupings of family as a base while they maintain multiple homes in other places, including the islands and villages of origin as well as overseas. This process reflected the fact that 'Isileli homes were primarily established, without cash-cropping land, as an access point into the stronger economy, educational institutions and movement opportunities provided by Tongatapu and the capital Nuku'alofa. As a result, short to medium term movements of outer island residents to 'Isileli households were common and frequent.

The origins and history of 'Isileli, with its population of recent arrivals from the outer islands and distant villages of Tongatapu, underscores the character of movement into and out of this village. As a result, movement often involves a general inflow of short and medium term movements to the village from other places, but also a reciprocal and frequent movement of people from 'Isileli to other places in Tonga. 'Isileli may therefore be characterised as a 'transit zone', a bridge for long-term movement elsewhere.

The maintenance of links to the village of origin plays an important and continuing role in these movements. This is particularly important in the context of 'Isileli as a village without 'api uta on which to grow cash and subsistence crops. The importance of maintaining connections to fonua (people and place of origin), as well as connection to family is therefore quite apparent, making it a predominant factor in movement. Education is also an important factor in movement to the village. The process involves young people from the outer islands but also distant villages of Tongatapu staying with family or kin in 'Isileli while going to one of the major secondary schools of Tongatapu. Conversely, for those leaving 'Isileli, work was cited as a reason for movement out of the household. In the main, this involved accessing employment opportunities within Tonga and overseas.

A useful case study illustrating the types of movement prevalent in 'Isileli is represented by a family of six, two parents and four children (two of whom attend secondary school), residing in four locations: in 'Isileli; in an outlying district of Tongatapu; on a remote island in Ha'apai; and in a southern state of America. At the time of the first census survey, the family structure and location of members was as follows: Sālote, the female head, who was working as a housemaid for a pālangi couple, and one daughter attending secondary school, were living in the house in 'Isileli; Aleki, the male head, the eldest daughter and her new husband, were living on the family 'api on an island in Ha'apai, tending the production of cash and subsistence crops on the family 'api uta 'bush 
allotment'; Siale, the eldest son had 'alu hola (run away) from his school class during a fundraising trip to the US and was currently living (without a visa) with a family of his käinga in Arizona; the youngest son was boarding at one of Tonga's secondary colleges.

This arrangement reflected the focus and situation of the family at the time. The flexibility inherent in the organisation of Tongan families however, allows for changing configurations as circumstances change. Eight months later, the family was arranged in the following way: Sālote and the youngest daughter were still living in the house in 'Isileli. At the end of the school year, the youngest son left his boarding school and joined the household. This segment of the family also travelled to the 'api in Ha'apai for Christmas; the eldest daughter and her husband continued tending the crops on the 'api uta in Ha'apai; Aleki, who had spent a short time in 'Isileli, travelled to the US to work and attend the marriage of Siale to a Tongan woman with permanent residence. Then, just five months later, the following configuration existed: Aleki joined his youngest son and daughter in the house in 'Isileli following his return from the US after six months with Siale and his new wife; the eldest daughter and her husband continued tending the cash and subsistence crops on their 'api uta in Ha'apai; Sālote travelled from 'Isileli to spend six months in the US with Siale and his new wife.

This case study demonstrates the flexibility and frequency of movement, and consequent impact on family configuration, associated with households in 'Isileli. It also highlights the need to maintain kinship and fonua links in the place of origin while also supporting the establishment of new nodes overseas. The case study also emphasises the importance of education as an activating agent for movement.

\section{Conclusion}

This paper has sought to demonstrate that the study of transnational connections is enriched when it accounts for local diversity in the type of connections and movements that can occur both in the country to which migrants travel as well as for those who remain 'at home' (for the time being at least), in the countries from which migrants have travelled.

As the case study has demonstrated, the nature of transnationalism is mediated by a range of factors that impact on the ability of people to move from one place to another. These factors include opportunities represented by the physical location of the village, access to education, employment, ability to undertake agricultural activities and proximity to local and international transport. Hence, there are differences in the opportunities available for transnational interaction for those living in outer island villages of Tonga such as Lotofoa in comparison to those living in a village such as Hofoa, located on the main island and close to the capital. 
Additionally, the case study seeks to dispel the notion of those remaining at 'home' as powerless individuals. Rather, as theorised in the structuration approach developed by Giddens (1984), migrants act are 'knowledgeable agents' who operate within migration institutions that regulate, operate and facilitate transnational interactions (Goss and Lindquist 1995, 331). As identified for Tonga, the migration institutions are founded upon kin, religion and connection to place (fonua).

In analysing transnational migrants and their interactions, migration studies have tended to forget about exploring the diasporic aspect of the lives of those who reside at 'home'. This study of Tongans has sought to provide a different perspective on these local transnational actors.

\section{References}

Basch, L, N. Glick-Schiller and C. Szanton Blanc. 1994. Nations unbound. Langhorne, Pa: Gordon and Breach.

Giddens, A. 1984. The constitution of society: Outline of the theory of structuration. Cambridge: Polity Press.

Goss, J. and B. Lindquist. 1995.Conceptualising international labour migration: A structuration perspective. The International Migration Review 29 (2): 317-51

Hannerz, U. 1992. Cultural complexity. New York: Columbia University Press.

Ong, A. 1999. Flexible citizenship: The cultural logics of transnationality. Durham: Duke University Press.

\section{ENDNOTES}

\footnotetext{
${ }^{1}$ Extra cash is generated as farm equipment is hired out to local farmers at critical points in the agricultural cycle.

${ }^{2}$ Hofoa is approximately three kilometres from Nuku'alofa. Most villagers drive cars, hitch lifts with a neighbour or friend, or catch the local bus that makes a round trip to the city every hour.

3 'Isileli is situated in the area commonly referred to as Sopu, which is the western extremity of the town of Kolomotu'a.
} 